\title{
TRIBUTAÇÃO E DESENVOLVIMENTO ECONÔMICO: O ICMS E SEU IMPACTO NAS OPERAÇÕES INTERESTADUAIS
}

\begin{abstract}
Resumo
O Imposto sobre Circulação de Mercadorias e Serviços (ICMS) é o principal imposto de competência dos entes federados estaduais no Brasil. Originalmente planejado para ser o subsídio financeiro da autonomia dos Estados, sua atual conformação fragiliza a condição desses entes e coloca em xeque o próprio pacto federativo. As operações interestaduais representam parcela considerável da economia brasileira. O ICMS incidente sobre essas operações é uma importante fonte de recursos para o setor público, entretanto a sistemática de cobrança e arrecadação desse tributo apresenta disfunções que comprometem o desenvolvimento econômico e alimentam acentuadas desigualdades regionais. A crescente dinâmica de comércio realizada por meio eletrônico tende ainda a reforçar os problemas dessa exação. Além disso, as obrigações acessórias atreladas ao imposto, em conjunto com seu intrincado mecanismo de concessão de créditos e compensação, eleva os custos de adequação das empresas e dificulta a exportação do produto nacional para o exterior. Romper com a limitação imposta por estes fatores é questão fundamental para maior crescimento econômico e inserção competitiva do país no mercado internacional.
\end{abstract}

Palavras-chave: ICMS, tributação, desigualdade regional, desenvolvimento econômico, competitividade econômica.

\begin{abstract}
Tax on Circulation of Goods and Services (ICMS) is the most important tax imposed by the state governments in Brazil. The ICMS is a typical value-added tax on consumption in the country. First it was planned to ensure the financial autonomy of these entities, but its current configuration weakens the self-government of states and undermines the federal pact. Interstate transactions represent a considerable portion of the Brazilian economy. The ICMS tax on these transactions is an important resource for governments, however the payment of this tax has unintended effects that harm economic development and imply regional inequalities. The growing e-commerce increases the problems of taxation. In addition, accessory tax obligations, together with its complex method of credit and compensation, raises business costs and affect the export of national products abroad. Overcome the limitation of these factors is the key for higher economic growth and competitive insertion of the country in the international environment.
\end{abstract}

Keywords: Value Added Tax, regional inequalities, economic development, international competitiveness.

\section{INTRODUÇÃO}


A relação entre o direito e a economia tem sido cada vez mais investigada. Isso se explica pelo fato de que, enquanto a ciência econômica objetiva encontrar soluções para a melhor forma de alocação de recursos escassos, a jurídica é instrumento de harmonização das relações sociais, tutelando direitos e garantias e, eventualmente, limitando as liberdades. Assim, as ciências jurídica e econômica podem se auxiliar mutuamente na busca de soluções para os problemas que afligem a sociedade.

A atividade fiscal de governo influencia a economia, seja através da aplicação de recursos públicos pelo processo político e orçamentário, seja pela arrecadação desses recursos, principalmente por meio da atividade tributária ${ }^{1}$.

Neste artigo procura-se investigar a relação entre essa segunda parte da atividade fiscal, a tributação, com o desenvolvimento econômico, tendo como objeto de análise o ICMS (Imposto sobre a Circulação de Mercadorias e Serviços), especificamente em seu aspecto relacionado a operações interestaduais.

O desenvolvimento nacional, assim como a redução das desigualdades em suas feições sociais e regionais, são objetivos fundamentais expressos pelo artigo $3^{\circ}$ da Constituição Federal do Brasil.

Sabe-se que um dos principais instrumentos estatais para minimizar desigualdades econômicas e regionais é a atividade fiscal em sua acepção distributiva ${ }^{2}$, já que o mercado é considerado um meio adequado para o alcance de eficiência econômica (exceto nos casos de falhas de mercado), mas que atuando de forma independente tende a não produzir resultados satisfatórios no sentido de maior equidade.

Espera-se da atuação estatal na economia, portanto, duas importantes finalidades: a primeira deve ser promover melhor distribuição dos recursos na sociedade, reduzindo as desigualdades, e a segunda está relacionada a permitir a atuação do mercado da forma mais eficientemente possível na geração de riquezas, promovendo o crescimento econômico.

Como será demonstrado ao longo do estudo, o ICMS como está hoje normatizado não contribui para essas duas finalidades, em boa parte devido ao seu intricado mecanismo de operações interestaduais. Pelo contrário, o sistema de tributação vigente reforça desigualdades regionais produzidas pelo mercado e ainda compromete a eficiência deste através de uma série de obrigações acessórias e de diferentes normas para cada ente da federação, muitas vezes não harmônicas entre si.

\footnotetext{
${ }^{1}$ Cf. LONGO, Carlos Alberto; TROSTER, Roberto Luis. Economia do Setor Público. São Paulo: Atlas, 1993.

${ }^{2}$ Sobre este assunto, ver a clássica definição de Musgrave (1974) sobre as funções fiscais.
} 
Essa forma inadequada de atuação do Estado brasileiro na economia compromete a distribuição de renda, a atração de novos investimentos e a competitividade internacional do país, compondo parte considerável do denominado "custo Brasil".

A fim de melhor compreender esses assuntos, este artigo discute nas seções seguintes as bases da atividade Estatal de tributação e seus mais importantes princípios. A seguir são apresentadas as principais características do ICMS, identificando-o como um imposto sobre o consumo. Após é apresentado o mecanismo de incidência do ICMS sobre as operações interestaduais e, em seguida, são trazidos à discussão os principais problemas advindos dessa forma de tributação, para além da guerra fiscal, assunto muito debatido em diversos outros estudos sobre o tema. Analisa-se a desigualdade regional propiciada pela atual sistemática de cobrança do ICMS nas operações interestaduais, a questão do comércio eletrônico, o crédito tributário nas operações de exportação e o custo de adequação das empresas.

\section{A ATIVIDADE ESTATAL DE TRIBUTAÇÃO}

A tributação surge da necessidade dos indivíduos em estabelecer convívio social organizado e gerir a coisa pública mediante a concessão de poder a um Soberano ${ }^{3}$. Como consequência, a condição necessária - mas não a única - para que o poder de tributar seja legítimo é que ele emane do Estado, visto que qualquer imposição tributária privada seria comparável à usurpação.

É por referir-se à construção do bem comum que se permite à tributação o poder de limitar a capacidade econômica individual em prol da criação de uma capacidade econômica social. O poder de tributar justifica-se sob a premissa de que o bem da coletividade tem preferência a interesses individuais, sobretudo porque, na ausência do Estado, não haveria garantia nem mesmo à propriedade privada.

As receitas tributárias são a principal forma de ingresso público nas economias modernas e a tributação, por seu modo, está regrada pelo direito, que disciplina as relações entre o Fisco e os contribuintes ${ }^{4}$. O Estado, para cumprir as funções que dele se espera e alcançar o bem comum, utiliza-se do instrumento da tributação, que consiste na expropriação

\footnotetext{
${ }^{3}$ Sobre este assunto, ver a teoria do contrato fiscal de Margareth Levi (1989)

${ }^{4}$ Segundo Martins (2011, p. 115) embora existam outras fontes capazes de fornecer dinheiro ao Estado, se for levado em conta as variáveis "quantidade relevante" e "perenidade", conclui-se que os tributos ostentam maior qualidade em vista das demais espécies, o que os torna os itens principais de receita pública na atualidade.
} 
lícita do patrimônio dos contribuintes, conforme o artigo $3^{\circ}$ do Código Tributário Nacional de 1966, que assim define tributo:

Art. $3^{\circ}$ Tributo é toda prestação pecuniária compulsória, em moeda ou cujo valor nela se possa exprimir, que não constitua sanção de ato ilícito, instituída em lei e cobrada mediante atividade administrativa plenamente vinculada.

O sistema tributário nacional é composto por várias espécies de tributos (impostos, taxas, contribuições de melhoria, contribuições e empréstimos compulsórios), com particularidades que devem ser estudadas não apenas sob o prisma jurídico, mas também das finalidades a que se destinam.

A Constituição Federal divide a competência tributária entre os entes federativos, estabelecendo em seus artigos 153, 155 e 156, a responsabilidade pela instituição de impostos respectivamente pela União, Estados e Distrito Federal e Municípios. O Código Tributário Nacional no artigo 16 define imposto como "tributo cuja obrigação tem por fato gerador uma situação independente de qualquer atividade estatal específica, relativa ao contribuinte".

Dessa forma, os impostos são arrecadados pelo Estado para garantir suas despesas gerais. Não é legalmente estabelecida qualquer relação entre a arrecadação dessa espécie de tributo e atuação estatal específica e nem está vinculado a qualquer princípio identificador de benefício direto dos contribuintes pagantes ${ }^{5}$. São exigidos sobre fatos praticados pelos respectivos sujeitos passivos da regra de incidência, em base de cálculo previamente estipulada. Logo, não pode o ente estatal tributar a revelia, sem prévia norma que autorize e discipline como a cobrança.

\section{OS PRINCÍPIOS TRIBUTÁRIOS}

Os princípios econômicos consubstanciam limites da atividade impositiva. A análise do alcance jurídico destes princípios evidencia tratar-se de vertentes ou subprincípios dos princípios jurídicos. A relação entre ambos é essencial para a concreção no plano fático e jurídico. Enquanto os princípios jurídicos “jurisdicizam" os conceitos trazidos pelos princípios econômicos, de maneira inversa, os princípios econômicos direcionam a aplicação dos princípios jurídicos no campo das finanças públicas.

\footnotetext{
${ }^{5} \mathrm{O} \S 1^{\circ}$ do art. 145 da Constituição Federal determina que os impostos, sempre que possível, devem ter caráter pessoal e graduação segundo a capacidade econômica do contribuinte.
} 
Joseph Stiglitz ${ }^{6}(1999)$ consigna que o tributo para ser eficiente deve ser equacionado segundo as seguintes características fundamentais:

- $\quad$ Neutralidade - motivo pelo qual não se deve distorcer os preços relativos provocando direcionamentos quanto à alocação de recursos na economia, sob pena de distorcê-la e tornar o sistema tributário ineficiente ${ }^{7}$;

- $\quad$ Simplicidade - princípio pelo qual deve haver simplicidade administrativa, tanto para o fisco quanto para o contribuinte, de modo a facilitar as atividades de fiscalização e arrecadação, bem como possibilitar ao contribuinte o exato conhecimento do que se paga e a quem se paga;

- Flexibilidade - consubstanciada na capacidade de se ajustar automaticamente às mutantes condições econômicas, sem perda de arrecadação;

- $\quad$ Progressividade e equidade (justiça) - implica tratar igualmente iguais e desigualmente situações desiguais na medida de suas desigualdades.

Do ponto de vista principiológico, Mizabel Derzi propugna que o imposto ideal para economias de mercado deve ser dotado dos seguintes atributos:

- é neutro, devendo ser indiferente tanto na competitividade e concorrência,quanto na formação de preços; - onera o consumo e nunca a produção ou o comércio, adaptando-se às necessidades de mercado; oferece maiores vantagens ao Fisco, pois sendo plurifásico, permite antecipar o imposto que seria devido apenas no consumo (vantagens financeiras), e coloca ademais todos os agentes econômicos das diversificadas etapas da industrialização e circulação como responsáveis pela arrecadação (vantagens contra o risco de insolvência). (DERZI, 2004, p. 343).

\section{O IMPOSTO SOBRE A CIRCULAÇÃO DE MERCADORIAS E SERVIÇOS (ICMS)}

Uma das características do federalismo é o que se designa de federalismo fiscal, através do qual é estabelecida a divisão de rendas tributárias entre os entes integrantes do Estado brasileiro. A Constituição Federal outorgou a cada um dos entes federados - União, Estados, Distrito Federal e Municípios - competências tributárias específicas. Segundo Carrazza (2012), a competência tributária pode ser definida como a aptidão desses entes em

\footnotetext{
${ }^{6}$ Joseph Stiglitz foi o vencedor do Prêmio Nobel de Economia em 2001.

${ }^{7}$ Cf. MOSQUERA, Roberto Quiroga. Tributação e Política Fiscal. In: Segurança Jurídica na tributação e estado de direito. São Paulo: Noeses, 2005, p. 571-572.
} 
criar determinados tributos. O diploma legal estabelece, de maneira rígida, a repartição de rendas tributárias, limitando a atuação de cada pessoa política interna.

A adoção de um regime rígido de repartição de competências é justificada como necessária para a manutenção da autonomia dos entes federativos, assegurando a cada unidade receita capaz de custear suas atividades.

\subsection{Principais características}

O inciso II, do artigo 155, da Constituição Federal de 1988, dispõe que compete aos Estados e ao Distrito Federal instituir o ICMS, Imposto sobre Operações Relativas à Circulação de Mercadorias e sobre Prestação de Serviços de Transporte Interestadual e Intermunicipal de Comunição. A rigor, este imposto contempla três hipóteses de incidência distintas: (i) circulação de mercadorias; (ii) prestação de serviço de transporte interestadual e intermunicipal; e (iii) prestação de serviço de comunicação.

O artigo 155 não apenas disciplina as hipóteses de incidência do ICMS, como também dispõe sobre as principais características do mesmo, estabelecendo as características básicas a serem observadas pela Lei Complementar e pela legislação interna dos entes federados, de maneira a imprimir unidade e uniformidade às normas relativas ao Imposto.

Dentre as principais características do ICMS, é importante ressaltar seu atributo de não cumulatividade, em que o contribuinte tem o direito constitucional de compensar o imposto incidente na operação por ele praticada com o montante cobrado nas operações anteriores.

Outra característica marcante do ICMS é a seletividade em função da essencialidade das mercadorias e dos serviços. A Constituição Federal do Brasil em seu artigo 155, § $2^{\circ}$, III, estabelece que este tributo "poderá ser seletivo em função da essencialidade das mercadorias e serviços". O critério da essencialidade emana do princípio constitucional da dignidade humana. Na menção à seletividade, o texto constitucional deixa assente que, mediante escolha de critérios definidos, caberá ao legislador ordinário a diferenciação entre produtos sujeitos a maior ou menor tributação. As alíquotas do ICMS deverão variar, para mais ou para menos, em razão da essencialidade das mercadorias e dos serviços. A comercialização dos gêneros considerados de primeira necessidade deverá, ao menos em tese, ser menos gravada pelo imposto do que aqueles considerados supérfluos. 
O ICMS é considerado o principal tributo dos Estados e, por suas particularidades, foi desenhado pelo legislador constituinte como um imposto de caráter nacional ${ }^{8}$. Trata-se de imposto do tipo usualmente denominado na área de estudos tributários como de Valor Agregado (IVA), em razão de seu atributo de não cumulatividade e por permitir que o consumo seja tributado ao longo da cadeia de produção, na medida em que é agregado valor aos insumos que comporão a mercadoria.

A unidade de tratamento do ICMS nos Estados realiza-se não somente pela abordagem constitucional da matéria, mas também pela demanda de Lei Complementar expressa na Constituição no artigo 155, $\S 2^{\circ}$, XII. Esses dispositivos, em conjunto, figuram como paradigma unificador das normas internas dos Estados, concedendo fundamento de validade às mesmas. Dessa forma, a organização do arcabouço normativo do ICMS é disposta de modo a permitir que sua lógica nacional opere ante a existência da legislação de diversos Estados e do Distrito Federal.

Esse mecanismo possibilita que um contribuinte em Minas Gerais faça valer o seu direito de crédito de ICMS decorrente de operação regularmente realizada com contribuintes de outros Estados, em que o ICMS tenha sido pago na origem. Devido ao caráter nacional do ICMS, admite-se que uma operação praticada nos limites de determinado Estado, portanto, sujeita apenas à legislação vigente no território desse ente federado, tenha validade e opere efeitos oponíveis na legislação interna de outro ente federado.

\subsection{A tributação sobre consumo}

Segundo dados da Organização para Cooperação e Desenvolvimento Econômico ${ }^{9}$ (OCDE), do total de impostos arrecadados no Brasil, apenas $21 \%$ incidem sobre a renda. Por outro lado, a tributação do país sobre consumo é bem mais elevada, totalizando $43 \%$ da arrecadação. Importante ressaltar que a metodologia da OCDE, que conduziu a esses resultados, não considerou entre esse tipo de tributo as contribuições sociais, que atualmente equivalem a mais de $26 \%$, consoante dados da mesma organização, e que indiretamente são em boa parte repassadas ao consumidor.

\footnotetext{
${ }^{8}$ Cf. BATISTA, Luiz Rogério Sawaya. Créditos do ICMS na Guerra Fiscal. São Paulo: Quartier Latin, 2012.

${ }^{9}$ Dados do estudo Revenue Statistics in Latin America (2014).
} 
Nenhum país considerado rico possui uma taxa nesses patamares de impostos sobre o cosumo, o que não é surpresa. Adotando-se a técnica de regressão linear entre coeficiente de Gini ${ }^{10}$ e percentual de carga tributária devido a tributos sobre o consumo, com dados da OCDE para países com população superior a 10 milhões de habitantes, é possível identificar a existência de forte correlação linear entre desigualdade social e utilização de impostos para consumo.

De maneira geral, pode-se dizer que o imposto sobre consumo é mais gravoso para pobres do que aos ricos. A razão para compreender esse fato é relativamente simples. Enquanto, um cidadão que ganha $\mathrm{R} \$ 30$ mil mensais possivelmente poupa ou investe parte considerável do seu salário, consumindo apenas uma parcela do mesmo, um outro cidadão que recebe apenas um salário mínimo, provavelmente consome tudo o que recebe, sem a possibilidade de poupar.

$\mathrm{O}$ aspecto de nações em desenvolvimento tributarem mais o consumo não permite distinguir ao certo se esta prática contribui para essas nações não serem desenvolvidas ou se é dada preferência a esse tipo de tributação justamente por não serem desenvolvidas.

De um lado, realmente é dificultoso aos países pobres arrecadar somente através de renda. No caso brasileiro, as pessoas com renda mensal superior a aproximadamente $\mathrm{R} \$ 2.000$ são oneradas pelo Imposto de Renda de pessoa física. Apesar de não se tratar de uma quantia elevada (inferior a três vezes o valor do salário mínimo), apenas 25 milhões de habitantes ${ }^{11}$ encontram-se nessa referida situação. Essas pessoas representam apenas $25 \%$ da população economicamente ativa, atualmente estimada pelo IBGE $^{12}$ em cerca de 100 milhões de pessoas.

Ainda é preciso considerar que é mais fácil sonegar a declaração do Imposto de Renda, dada a existência de altos índices de informalidade no país e a capacidade das elites bloquearem o imposto sobre a renda, do que simplesmente se manifestar no sentido de não pagar a carga tributária embutida na compra de um gênero alimentício no supermercado.

\footnotetext{
${ }^{10}$ O Índice de Gini, criado pelo matemático italiano Conrado Gini em 1912, é um parâmetro internacional utilizado para medir o grau de concentração de renda em determinado grupo. Ele aponta a diferença entre os rendimentos dos mais pobres e dos mais ricos. Numericamente, varia de zero a um. O valor zero representa a situação ótima de igualdade, ou seja, todos têm a mesma renda. O valor um representa a situação de completa desigualdade. O coeficiente de Gini se calcula como uma razão das áreas no diagrama da curva de Lorenz, que neste caso é aplicada considerando a renda das pessoas no eixo das ordenadas e, nas abscissas, o número cumulativo de pessoas de um grupo, consideradas em ordem crescente de renda.

${ }^{11}$ Disponível em: http://www.receita.fazenda.gov.br/AutomaticoSRFsinot/2013/04/30/2013_04_30_19_09_49_1 062007516.html. Acesso em: 02/03/2014.

${ }^{12}$ Pesquisa Nacional por Amostra de Domicílios 2011-2012.
} 
De outro lado, também é fato que as alíquotas brasileiras de imposto de renda não são tão elevadas se comparadas em âmbito internacional. Essas alíquotas vão de $0 \%$ até 27,5\%. Nos Estados Unidos, não existe isenção nem mesmo para os salários mais baixos, que devem contribuir com $10 \%$. Neste mesmo país, a alíquota pode chegar até a 39,6\% no caso das rendas mais elevadas. $\mathrm{Na}$ Inglaterra, este valor pode alcançar $45 \%$ e muito mais nos países escandinavos.

No Brasil, o imposto mais importante que incide sobre o consumo é o ICMS, imposto este de competência estadual e caráter nacional, conforme explanado na seção anterior. Segundo dados do Ministério da Fazenda ${ }^{13}$, em 2012 a arrecadação total deste imposto foi de cerca de $\mathrm{R} \$ 327$ bilhões.

Entretanto, é preciso tratar esses assuntos com cautela. Pode-se chegar à conclusão que se tributa muito o consumo no Brasil ou então que, diferentemente, se tem essa impressão por conta da baixa participação dos tributos sobre a renda na composição da arrecadação nacional. De fato, a menor renda per capita média do país frente a países desenvolvidos e as menores alíquotas de impostos incidentes sobre a renda, indicam que um dos motivos da grande participação dos tributos sobre consumo na arrecadação nacional não seria exclusivamente relacionado à grande tributação sobre o consumo, mas também à baixa tributação sobre renda.

O ICMS no Brasil, principal imposto sobre o consumo no país, por exemplo, possui alíquotas compatíveis com o seu equivalente europeu chamado de VAT (Value Added Tax). A alíquota desse imposto é fixada por cada Estado-Membro da União Europeia e não pode ser inferior a 15\% até 31 de Dezembro de 2015, segundo a diretiva 2006/112/CE do Conselho da União Europeia. No Reino Unido, por exemplo, o valor da alíquota desse imposto é atualmente $20 \%$.

Na realidade, admite-se que a tributação sobre o consumo exerce peso considerável na economia do país. Entretanto, esse problema pode ser imputado mais à incidência conjunta ao ICMS de outros tributos indiretos sobre o consumo (como PIS e COFINS, que operam em efeito cascata, sem o mecanismo da não cumulatividade) do que propriamente à alíquota desse imposto. Ainda assim, permanece verdadeiro o argumento de que a grande participação do consumo na receita pública brasileira é também, em parte, contribuição da baixa participação da tributação sobre a renda.

\footnotetext{
${ }^{13}$ Cf. CONFAZ - Conselho Nacional de Política Fazendária. Ministério da Fazenda. Boletim do ICMS e demais impostos estaduais (2012). Disponível em: http://www1.fazenda.gov.br/confaz/boletim/. Acesso em $14 / 02 / 2014$.
} 


\section{ICMS NAS OPERAÇÕES INTERESTADUAIS}

O ICMS é um imposto de competência estadual. Esta informação por si é suficiente para compreender como se dá a tributação de algo produzido, comercializado e vendido ao consumidor final dentro de um mesmo Estado da federação. Entretanto, essa compreensão pode não ser tão simples e intuitiva quando essas operações ocorrem entre contribuintes situados em Estados diferentes.

A Constituição Federal de 1988 estabeleceu regras que disciplinam esta situação. Essas regras, que permitem a divisão do tributo devido entre os entes envolvidos na operação, serão analisadas na próxima seção.

\subsection{O funcionamento}

A adequada compreensão dos problemas gerados pelo regime de tributação do ICMS passa antes pela compreensão de seus mecanismos de funcionamento nas operações interestaduais.

Nesse sentido, o primeiro dispositivo a ser observado é o enunciado pelo artigo $155, \S$ $2^{\circ}$, inciso VI, da Constituição Federal, segundo o qual, salvo deliberação em contrário dos Estados e do Distrito Federal, nos termos de Lei Complementar que disciplina o assunto, as alíquotas internas não poderão ser inferiores às previstas para as operações interestaduais. Estas alíquotas, por sua vez, são fixadas pelo Senado Federal.

Essa norma é de elevada relevância, visto que através da mesma é assegurada ao Estado consumidor uma parcela da receita tributária produzida pelas operações interestaduais. Essa fatia que cabe ao Estado consumidor poderá ser maior ou menor do que aquela pertencente ao Estado produtor, dependendo da combinação dos valores da alíquota interestadual, da alíquota interna do Estado consumidor e do valor de revenda da mercadoria nestes Estados.

Os incisos VII e VIII do referido artigo da Constituição são pontos centrais para entendimento do método de cobrança do ICMS nas operações interestaduais. Para ilustrar a 
aplicação dessas regras, supõe-se três situações hipotéticas em que uma empresa domiciliada em São Paulo vende uma mercadoria a outra domiciliada no Ceará, considerando as seguintes alíquotas:

- Alíquota Interestadual (SP - CE) $=9 \%$

- Alíquota interna de São Paulo $=18 \%$

- Alíquota interna do Ceará $=15 \%$

Na primeira situação o comprador no Ceará é um consumidor final (não comerciante) e adquire a mercadoria de uma empresa paulista via internet ou telefone. Neste caso não existe diferença em aspectos tributários entre este tipo de operação e aquela em que o comprador, viajando por São Paulo, adquire o produto diretamente da empresa comerciante. Nos dois casos é aplicável a alíquota interna do Estado de São Paulo (18\%).

Na segunda situação, o comprador cearense é comerciante. Entretanto, apesar de ser comerciante, adquire o produto na condição de consumidor final, sem o objetivo de comercializá-lo. Seria o caso, por exemplo, da empresa comercial que adquire máquinas para compor seu ativo permanente. Nesta ocasião, o texto constitucional determina que a arrecadação seja dividida entre o Estado de origem (SP) e o de destino da mercadoria (CE). Dessa forma, o Estado de São Paulo deverá arrecadar quantia correspondente à alíquota interestadual (9\%) e ao Estado do Ceará caberá receber a diferença entre sua alíquota interna e a alíquota interestadual $(15 \%-9 \%=6 \%)$.

$\mathrm{Na}$ terceira situação, tem-se o exemplo mais comum, em que se aplica o mecanismo de débitos e créditos típico do regime de não cumulatividade do ICMS. O comprador no Ceará é comerciante e adquire a mercadoria com o objetivo de revendê-la no comércio local. Neste caso, o Estado de origem (SP) arrecadará valor relativo à alíquota interestadual (9\%). O comerciante cearense, por sua vez, terá direito ao crédito do ICMS pago na aquisição da mercadoria e compensará este valor em vendas futuras. Supondo que a mercadoria seja adquirida por $\mathrm{R} \$ 1.000,00$ e seja revendida por $\mathrm{R} \$ 1.400,00$. O Estado de São Paulo receberá $\mathrm{R} \$ 90,00$ em virtude da aplicação da alíquota interestadual sobre a primeira venda. Na operação de venda no Ceará, o ICMS incidirá através da alíquota interna deste Estado no valor da segunda operação, o que perfaz $\mathrm{R} \$ 210,00$. Neste valor será abatido o crédito adquirido na primeira compra, o que resulta em um montante a recolher no Estado do Ceará equivalente a $\mathrm{R} \$ 120,00$.

As duas primeiras situações são disciplinadas pelos incisos VII e VIII do $\S 2^{\circ}$ do artigo 155 da Constituição Federal, cuja transcrição faz-se a seguir: 
VII - em relação às operações e prestações que destinem bens e serviços a consumidor final localizado em outro Estado, adotar-se-á:

a) a alíquota interestadual, quando o destinatário for contribuinte do imposto;

b) a alíquota interna, quando o destinatário não for contribuinte dele;

VIII - na hipótese da alínea a do inciso anterior, caberá ao Estado da localização do destinatário o imposto correspondente à diferença entre a alíquota interna e a interestadual.

A primeira situação é disciplinada pelo inciso VII, alínea $b$. A segunda é regulada pela combinação do inciso VII, alínea $a$, com o inciso VIII. A terceira situação, por sua vez, é regida pela regra geral da não cumulatividade disposta pelo artigo $155, \S 2^{\circ}$, inciso I, da Constituição Federal.

\subsection{Problemas do modelo adotado}

A redução das desigualdades sociais e regionais constitui uma das facetas do desenvolvimento econômico e consubstancia a função distributiva da atividade fiscal dos governos. O atual desenho institucional do ICMS pouco contribui para o desenvolvimento econômico nacional, no que diz respeito à redução das desigualdades regionais. Além disso, seu excessivamente complexo sistema de cobrança e compensação compromete a eficiência e a competitividade da economia nacional, conforme será debatido nos próximos tópicos.

\subsubsection{ICMS e desigualdade regional}

A Constituição Federal de 1988, no desenho institucional do ICMS, atribuiu competência aos Estados-membros para a arrecadação deste importante imposto. Entretanto, após definida a competência estadual para a exação deste tributo pelo Poder Constituinte, tornou-se questão igualmente relevante a definição de competências nas operações realizadas entre contribuintes situados em diferentes entes federados. Uma possibilidade seria a competência de arrecadação pertencer ao Estado que produziu a mercadoria (alienante) e a outra, diametralmente oposta, seria tal incumbência pertencer ao Estado em que ocorreu o consumo (adquirente). 
A primeira solução, visivelmente favorável aos estados produtores, beneficia os entes federados mais industrializados e que conseguem produzir mais mercadorias. De outro lado, a segunda possibilidade, ao eleger o Estado em que ocorreu o consumo como responsável pela arrecadação, possibilita maior arrecadação dos Estados menos desenvolvidos, colaborando para o objetivo constitucional, expresso no artigo $3^{\circ}$, inciso IV, de redução das desigualdades regionais do país.

Nas discussões ocorridas na Assembleia Nacional Constituinte de 1987, venceram os Estados produtores (mais desenvolvidos). A composição dessa Assembleia por um número de deputados aproximadamente seis vezes maior do que a participação de senadores certamente influenciou essa decisão ${ }^{14}$.

Enquanto os deputados são considerados representantes do povo e são eleitos em número proporcional ao tamanho da população de seus respectivos Estados, os senadores representam os Estados da federação e, por isso, são eleitos em igual quantidade por cada um desses membros, conforme dispõem os artigos 45 e 46 da Constituição Federal:

Art. 45 A Câmara dos Deputados compõe-se de representantes do povo, eleitos, pelo sistema proporcional, em cada Estado, em cada Território e no Distrito Federal.

(...)

Art. 46. O Senado Federal compõe-se de representantes dos Estados e do Distrito Federal, eleitos segundo o princípio majoritário.

A ampla composição do Poder Constituinte por deputados, aumentando a representação dos Estados mais populosos e com maiores economias, seguramente influenciou a decisão sobre a configuração do ICMS nas operações interestaduais que premia Estados produtores em detrimento dos demais.

Em contrapartida, criaram-se regras que asseguram que nas operações interestaduais realizadas entre contribuintes uma parcela razoável da arrecadação da cadeia de produção pertenceria ao ente federado em que ocorre o consumo.

Não é difícil perceber que houve falta de razoabilidade na definição da sistemática de cobrança do ICMS, pois todos os Estados são considerados, em maior ou menor escala, consumidores. Diferentemente, nem todos podem ser considerados produtores. Uma consequência é a concentração da arrecadação nestes poucos Estados produtores.

Exemplificando, em uma situação hipotética extrema em que apenas um Estado produz tudo o que é consumido em um país, este Estado produtor, além de arrecadar sobre o

\footnotetext{
${ }^{14}$ Cf. OLIVEIRA, Mauro Márcio. Fontes de informações sobre a Assembléia Nacional Constituinte de 1987: quais são, onde buscá-las e como usá-las. Brasília: Senado Federal, 1993.
} 
consumo realizado internamente em seu território, também arrecadará através de todas as operações interestaduais com cada um dos outros Estados da federação. Na situação real, menos exagerada do que o exemplo, o Estado de São Paulo seria comparável a este único estado produtor.

De fato, quando se analisa a arrecadação de ICMS das unidades federativas do Brasil, segundo dados de 2012 do Ministério da Fazenda, percebe-se que, a cada $\mathrm{R} \$ 3,00$ arrecadados de ICMS por todos os 26 Estados do Brasil e o Distrito Federal, aproximadamente R\$1,00 é arrecadado somente pelo Estado de São Paulo e aproximadamente R \$ 2,00 são arrecadados apenas pelo conjunto dos Estados de São Paulo, Minas Gerais, Rio de Janeiro, Rio Grande do Sul, Paraná e Bahia.

TABELA 1

ICMS por Unidade da Federação

\begin{tabular}{|c|c|c|c|}
\hline Estado & $\begin{array}{c}\text { Receita ICMS } \\
(\mathbf{M i l ~ R} \mathbf{\$})^{\mathbf{1}}\end{array}$ & $\begin{array}{c}\text { ICMS Per } \\
\text { Capita }(\mathbf{R} \$)^{\mathbf{2}}\end{array}$ & $\begin{array}{c}\text { Produto Interno } \\
\text { Bruto (Mil R\$) }^{\mathbf{3}}\end{array}$ \\
\hline São Paulo & 109.103 .539 & 2603,83 & 1.349 .465 .000 \\
Minas Gerais & 32.100 .033 & 1616,70 & 386.156 .000 \\
Rio de Janeiro & 25.466 .802 & 1568,99 & 462.376 .000 \\
Rio Grande do Sul & 21.378 .209 & 1984,87 & 263.633 .000 \\
Paraná & 17.859 .740 & 1688,42 & 239.366 .000 \\
Bahia & 14.442 .792 & 1018,87 & 159.869 .000 \\
Santa Catarina & 12.719 .389 & 1992,61 & 169.050 .000 \\
Goiás & 11.369 .285 & 1847,16 & 111.269 .000 \\
Pernambuco & 10.601 .777 & 1187,07 & 104.394 .000 \\
Espírito Santo & 9.222 .390 & 2577,48 & 97.693 .000 \\
Ceará & 7.646 .410 & 888,50 & 87.982 .000 \\
Mato Grosso & 6.708 .830 & 2153,49 & 71.418 .000 \\
Amazonas & 6.500 .920 & 1810,34 & 64.555 .000 \\
Pará & 6.266 .122 & 804,12 & 88.371 .000 \\
Mato Grosso do Sul & 6.005 .121 & 2397,17 & 49.242 .000 \\
Distrito Federal & 5.693 .957 & 2149,85 & 164.482 .000 \\
Maranhão & 3.858 .928 & 574,73 & 52.187 .000 \\
Rio Grande do Norte & 3.690 .518 & 1143,21 & 36.103 .000 \\
Paraíba & 3.248 .745 & 851,53 & 35.444 .000 \\
Rondônia & 2.623 .797 & 1650,18 & 27.839 .000 \\
Alagoas & 2.453 .754 & 775,16 & 28.540 .000 \\
Piauí & 2.395 .316 & 757,83 & 24.607 .000 \\
Sergipe & 2.301 .428 & 1090,28 & 26.199 .000 \\
Tocantins & 1.491 .368 & 1051,97 & 18.059 .000 \\
Amapá & 695.796 & 996,24 & 8.968 .000 \\
Acre & 498.744 & 657,29 & 8.794 .000
\end{tabular}




\begin{tabular}{|c|c|c|c|} 
Roraima & 417.149 & 888,45 & 6.951 .000 \\
\hline Total & $\mathbf{3 2 6 . 7 6 1 . 0 3 9}$ & $\mathbf{1 6 8 4 , 8 0}$ & $\mathbf{4 . 1 4 3 . 0 1 2 . 0 0 0}$ \\
\hline
\end{tabular}

Elaboração própria

Fontes: 1 - CONFAZ. Boletim do ICMS e demais impostos estaduais, 2012.

2 - IBGE. Estimativas de população para $1^{\circ}$ de julho de 2012.

3 - IBGE. Contas Regionais do Brasil, 2011.

Por meio da tabela 1, verifica-se que, em 2012, a região Sudeste, com o importante desempenho de São Paulo, é responsável por 53,8\% da arrecadação nacional de ICMS. De outro lado, Estados como Acre, Roraima e Amapá respondem cada um por menos de 0,2\% dessa arrecadação. Estados do Nordeste como Piauí e Sergipe respondem por 0,7\%.

De modo semelhante, cotejando os dados de arrecadação de ICMS no ano de 2012, verifica-se que a região Norte responde por apenas 5,6\% da arrecadação nacional de ICMS e a região Centro-Oeste, incluindo o Distrito Federal, por apenas 9,1\%. Esses números oferecem uma dimensão da reduzida capacidade econômica dos Estados mencionados e das próprias regiões.

Através da análise dos dados é possível identificar uma nítida correlação entre arrecadação de ICMS e o tamanho da economia do Estado. Essas variáveis são possivelmente causas recíprocas da outra, pois se por um lado é evidente que um ente de economia maior deverá arrecadar mais tributos, de outro não é menos verdade que um Estado com menor arrecadação possuirá menor capacidade de investimento em infraestrutura e, consequentemente, terá reduzido potencial de atração de investimento privado. Percebe-se que as regras de arrecadação do ICMS adotadas pelo país não favorecem o rompimento dessa lógica. Em alguns, pelo contrário, chega até mesmo a estimulá-la, como no exemplo de São Paulo, em que o PIB representa 32,57\% do país e a fatia de arrecadação do ICMS representa $33,39 \%$. Ao passo que Estados como o Acre representa $0,21 \%$ da economia do país, mas recebe apenas $0,15 \%$ de todo ICMS arrecadado no Brasil.

Segundo dados do Instituto de Pesquisa Econômica Aplicada (IPEA), o índice de Gini $^{15}$ do Brasil em 2012 foi de 0,522. O mesmo índice em 2002, segundo dados do CPS/FGV a partir de microdados da PNAD/IBGE, era de 0,588. Essa melhora no índice ao longo da última década está relacionada às políticas públicas, incluindo as políticas de aumento do salário mínimo e transferências de rendas.

Utilizando-se a mesma técnica de análise do índice de Gini, considerando, entretanto, em vez da desigualdade social a desigualdade regional, sob a ótica da arrecadação do

\footnotetext{
${ }^{15}$ Ver definição na seção 4.2 deste artigo
} 
principal tributo estadual, o ICMS, é obtido o valor de 0,611. Este resultado, indicando ser a desigualdade regional sensivelmente superior à desigualdade social, sugere que este problema deverá ocupar o centro das atenções governamentais nos próximos anos, sob pena de comprometer a própria redução das desigualdades sociais, que há anos vem sido buscada no Brasil.

$\mathrm{Na}$ tabela 2, são exibidos os dados relativos às outras receitas tributárias dos Estados (excluída a receita com ICMS). Os Estados e as regiões que possuem fraco desempenho na arrecadação de ICMS também possuem esse desempenho quanto à arrecadação tributária, o que denota a frágil economia interna.

TABELA 2

Outras Receitas Tributárias por Estado em 2012

\begin{tabular}{|c|c|c|}
\hline Estado & $\begin{array}{c}\text { Participação na } \\
\text { Receita }\end{array}$ & Receita (Mil R\$) \\
\hline São Paulo & $39,33 \%$ & 285.787 .515 \\
Rio de Janeiro & $19,54 \%$ & 141.990 .394 \\
Distrito Federal & $9,87 \%$ & 71.711 .053 \\
Paraná & $5,30 \%$ & 38.497 .789 \\
Minas Gerais & $5,28 \%$ & 38.382 .635 \\
Rio Grande do Sul & $4,45 \%$ & 32.305 .920 \\
Santa Catarina & $3,22 \%$ & 23.426 .780 \\
Espírito Santo & $1,96 \%$ & 14.269 .218 \\
Bahia & $1,91 \%$ & 13.890 .400 \\
Pernambuco & $1,74 \%$ & 12.668 .823 \\
Amazonas & $1,23 \%$ & 8.958 .753 \\
Goiás & $1,17 \%$ & 8.496 .678 \\
Ceará & $1,12 \%$ & 8.152 .273 \\
Maranhão & $0,60 \%$ & 4.379 .151 \\
Pará & $0,59 \%$ & 4.291 .894 \\
Mato Grosso & $0,49 \%$ & 3.579 .881 \\
Mato Grosso do Sul & $0,37 \%$ & 2.686 .915 \\
Paraíba & $0,35 \%$ & 2.547 .193 \\
Rio Grande do Norte & $0,34 \%$ & 2.478 .513 \\
Sergipe & $0,26 \%$ & 1.872 .268 \\
Alagoas & $0,22 \%$ & 1.598 .184 \\
Piauí & $0,20 \%$ & 1.417 .239 \\
Rondônia & $0,17 \%$ & 1.271 .519 \\
Tocantins & $0,10 \%$ & 743.642 \\
& & \\
\hline
\end{tabular}

\footnotetext{
${ }^{16}$ Os tributos considerados na elaboração desta tabela foram o Imposto sobre Exportação (IE), Imposto sobre Importação (II), Imposto sobre Produtos Industrializados (IPI), Imposto de Renda de pessoas físicas e jurídicas (IRPF e IRPJ), Imposto sobre Operações Financeiras (IOF), Imposto sobre a Propriedade Territorial Rural (ITR), Contribuição para Financiamento da Seguridade Social (COFINS), Contribuição aos Programas de Integração Social e de Formação do Patrimônio do Servidor Público (PIS/PASEP), Contribuição Social sobre o Lucro Líquido (CSLL), Contribuição de Intervenção no Domínio Econômico sobre Combustíveis (CIDECombustíveis), Contribuições para o Regime de Previdência dos Servidores e outras receitas.
} 


\begin{tabular}{|c|c|c|} 
Amapá & $0,06 \%$ & 461.890 \\
Roraima & $0,06 \%$ & 418.394 \\
Acre & $0,05 \%$ & 385.310 \\
\hline Total & $100,00 \%$ & 726.670 .221 \\
\hline
\end{tabular}

Fonte: Receita Federal

Elaboração própria

Os Estados com baixa arrecadação na tabela 2, geralmente possuem também baixo Produto Interno Bruto, evidenciando a fragilidade econômica dos mesmos ${ }^{17}$. Dessa forma, esses entes federados tornam-se bastante dependentes de repasse de recursos da União.

Essa situação demonstra problemas estruturais do federalismo fiscal brasileiro, em que determinadas unidades federadas sequer conseguem gerar os recursos que necessitam para suas atividades estatais, em virtude de seus ínfimos setores de comércio, indústria e serviços.

Nas palavras de Batista (2012, p. 119), a atual configuração do sistema tributário e financeiro do país torna difícil qualquer rompimento com a lógica posta, visto que "resta evidente que essas mesmas unidades federadas fragilizadas economicamente possuem poucas condições de atração de investimentos, seja sob o ponto de vista da capacidade financeira do Estado de estimular a sua própria economia, seja sob a óptica de elementos atrativos ao investimento, como proximidade de mercado consumidor e infraestrutura”.

A dependência econômica e financeira desses Estados tende a ter implicações também na esfera política, principalmente sob a forma de redução da autonomia desses entes federados, porquanto os mesmos passam a ter seus recursos condicionados à barganha no processo político ou ao atendimento de condições técnicas estabelecidas pelo poder central. Essa situação evidencia a fragilidade do federalismo vigente hoje no Brasil.

\subsubsection{O comércio eletrônico}

\footnotetext{
${ }^{17}$ O estudo de Luiz Guilherme de Oliveira (2000, p. 49) chama atenção para o fato de que determinados Estados obtêm receitas superiores, decorrentes do repasse do Fundo de Participações dos Estados, do que da própria arrecadação de ICMS:

"Podemos observar acima que a Constituição de 1988 possibilitou uma ampliação na capacidade financiadora das UF, principalmente através das transferências dos FPE. É importante destacar que o FPE representa 76\% das transferências federais aos Estados, logo, sua importância é fundamental para o financiamento das UF. Com a ampliação do volume transferido através do FPE, muitas UF passaram a abrir mão do volume a ser arrecadado através, principalmente, do ICMS, em especial aquelas que possuem uma arrecadação reduzida deste tributo. Como consequência deste processo, a UF deixa de ampliar sua receita tributária, diminuindo assim o volume de transferências da esfera estadual para a esfera municipal, penalizando, indiretamente, os municípios sob sua influência."
} 
A evolução tecnológica das últimas décadas provocou mudanças substanciais na maneira como a humanidade realiza suas mais diversas atividades. As transações comerciais também sofreram o impacto dessas transformações e foram fortemente alteradas por essa nova realidade.

O imposto ideal deve possuir flexibilidade suficiente para se adaptar às mudanças tecnológicas, sem a necessidade de grandes reformas em seus mecanismos normativos. Essa característica é importante por evitar que a arrecadação de determinado tributo sofra grandes perdas em virtude de alterações fáticas não captadas pelo fato gerador da exação ${ }^{18}$.

A evolução das telecomunicações e da informática permitiu o surgimento do advento do comércio eletrônico. Esta atividade possibilita que compradores geograficamente muito distantes dos vendedores comercializem entre si através da rede mundial de computadores. O’Connell (2002) define comércio eletrônico como sendo todas atividades de compra ou venda de bens, produtos, serviços ou informações eletronicamente.

Em que pese esse fenômeno possuir relevantes repercussões no âmbito jurídico sobre a adequação das normas a essa nova modalidade de intercâmbio comercial, interessa saber as consequências econômico-financeiras aos entes federados. Sobre as implicações econômicas do comércio eletrônico, é relevante saber que:

\begin{abstract}
A redução do número de intermediários, ou mesmo a extinção deles, pode eventualmente dificultar para a administração tributária a obtenção de informações a respeito do negócio jurídico realizado, mas também pode proporcionar uma economia para o vendedor (que servirá para compensar os gastos realizados com a manutenção do sistema de vendas pela internet) e uma redução de preço para o consumidor final (uma vez que não será necessário remunerar o intermediário). (CEZAROTI, 2005, p.154).
\end{abstract}

O comércio eletrônico caracteriza-se pela redução de custos, inexistência de limite territorial e disponibilidade ininterrupta de funcionamento. Uma loja online pode comercializar 24 horas por dia, inclusive fora de dias úteis, e suas mercadorias podem ficar disponíveis para o mundo inteiro. Nessa modalidade de comércio há uma relevante redução de custos com aluguel, decoração, funcionários e outras despesas fixas de um estabelecimento tradicional.

Por outro lado, do ponto de vista fiscal e tributário, a questão central sobre o comércio eletrônico é identificar a qual ente federado compete tributar as operações interestaduais, já que essa modalidade de comércio estimula e facilita esse tipo de transação.

\footnotetext{
${ }^{18}$ Cf. CARDOSO, Daniel Gatschnigg. Limites da Tributação do Comércio Internacional e Desenvolvimento Econômico. São Paulo: Quartier Latin, 2010, p.160.
} 
A Lei Complementar $n^{\circ} 87 / 96$ em seu artigo 11, inciso I, alínea $a$, determina como principal regra para a definição do local de ocorrência do fato gerador do ICMS, o local do estabelecimento onde se localizar a mercadoria no instante da ocorrência do fato gerador, que é a saída do estabelecimento.

Sacha Calmon e Mizabel Derzi ${ }^{19}$ definem estabelecimento como uma unidade econômica da empresa, com administração e gerência (ainda que reduzidas), apta ao exercício de uma atividade econômica.

O ICMS interestadual incide quando um produto ou serviço é fornecido por estabelecimento de determinado estado e vendido a outro. Nestas operações a arrecadação de parte do ICMS cabe ao Estado de origem da mercadoria e outra parte ao Estado de destino. Entretanto, quando a compra é realizada pela internet, o fato gerador do ICMS só ocorre na origem. Nesta situação, o recolhimento do referido imposto compete integralmente aos Estados de origem da mercadoria, aplicando-se a alíquota interna conforme o artigo 155, $\S 2^{\circ}$, inciso VII, alínea $b$ da Constituição Federal, o que implica queda de arrecadação aos entes federados considerados consumidores.

Nessas transações, apenas é possível a repartição de receitas entre os Estados, na eventualidade em que a operação, realizada por meio eletrônico, possua finalidade mercantil, também chamada no e-commerce de operação B2B (business-to-business).

Por outro lado, as compras feitas na internet diretamente pelo consumidor final, também denominada de operação B2C (business-to-consumer), aplica-se a alíquota interna do Estado de origem por não envolver estabelecimento contribuinte do imposto no Estado de destino.

Conforme alguns autores, estas operações interestaduais diretas ao consumidor final resultam em perda de renda significativa para os Estados consumidores:

\begin{abstract}
A partir do ano de 2002 as vendas interestaduais a consumidor final, não contribuinte do ICMS, vêm crescendo e é uma tendência de não parar de crescer, isso faz com que os demais Estados consumidores transfiram renda para os Estados onde inicia a operação da mercadoria, fato esse que fomenta mais a desigualdade, no que se diz respeito à distribuição de riquezas, entre os Estados da Federação. A maioria dos Estados da Federação transferem riquezas para uma minoria nestas operações de comércio eletrônico. (ALEXANDRIA; CARVALHO, 2011).
\end{abstract}

\footnotetext{
${ }^{19}$ Cf. DERZI, Mizabel Abreu Machado; COÊLHO, Sacha Calmon Navarro. O aspecto espacial da regra-matriz do Imposto Municipal sobre Serviços, à luz da Constituição. In: Revista Dialética de Direito Tributário, São Paulo, v.88, jan. 2003, p. 137.
} 
Com o acesso crescente da rede mundial de computadores, cada vez mais consumidores podem adquirir produtos em lojas virtuais de produtores situados em estados que não o de sua residência. Dessa maneira, parcela do ICMS que seria devida ao estado em que é domiciliado o comprador (equivalente à diferença entre a alíquota interna e a alíquota interestadual) será arrecadada pelo estado onde estiver o estabelecimento do qual sairá o produto, de forma que ocorrerá um deslocamento de arrecadação tributária dos estados consumidores para os produtores, agravando a questão das operações interestaduais convencionais expostas na seção anterior. Essa situação é uma franca desobediência da disposição constitucional sobre o objetivo nacional de redução das desigualdades regionais.

Segundo estudo da América Economía Intelligence, encomendado pela empresa de cartões de crédito VISA, ao final de 2011 o comércio eletrônico alcançou 1\% do Produto Interno Bruto (PIB) nacional. No mesmo período, segundo dados da Federação do Comércio do Rio de Janeiro (FECOMERCIO-RJ), em parceria com a Fundação Getúlio Vargas, o comércio representou 38\% do PIB do país. O aspecto mais impressionante do comércio eletrônico, no entanto, é relativo ao crescimento do setor. Segundo dados da consultoria E-bit, especializada em comércio eletrônico, o crescimento do setor foi de $20 \%$ em 2012 e $28 \%$ em 2013.

Um marco importante para o assunto em foco ocorreu no ano 2000, quando convênio realizado no âmbito do CONFAZ (MINISTÉRIO DA FAZENDA, 2001), entre os Estados e Distrito Federal, disciplinou o conflito criado pelas montadoras de automóveis, que vendiam diretamente ao consumidor pela internet, repartindo a base de calculo do ICMS em 55\% para o Estado de origem e $45 \%$ para o Estado de destino, quando da realização de vendas interestaduais.

Contudo, esta solução não se aplica às outras mercadorias comercializadas no meio eletrônico, gerando uma guerra fiscal com aspectos diferentes da tradicional - que se baseia na política de concessão de benefícios fiscais. A guerra fiscal do e-commerce funda-se na disputa do Estado de destino em receber parte das receitas recolhidas pelo Estado de origem.

Para tentar solucionar este problema, em 2011 dezoito estado brasileiros, firmaram o Protocolo ICMS 21/2011, celebrado no CONFAZ, o qual determina que estes entes federados devem exigir a parcela de ICMS sobre "operações interestaduais em que o consumidor final adquire mercadoria ou bem de forma não presencial”, repartindo a receita nestas operações.

O protocolo estabelece que, nas operações interestaduais entre os Estados signatários, o estabelecimento remetente, na condição de substituto tributário, deve recolher o ICMS em 
favor da unidade federada de destino, referente à parte cabível a esta. Esta parcela é exigível a partir do instante da entrada da mercadoria no território do Estado de destino, inclusive na eventualidade de a mercadoria ser proveniente de Estado não signatário do Protocolo.

Desafortunadamente, entretanto, o protocolo não solucionou a questão da guerra fiscal no comércio eletrônico, porquanto a maioria dos estabelecimentos que praticam o comércio online, segundo Kubota e Milani (2011, p. 20), estão situados nos Estados de São Paulo, Rio de Janeiro e Minas Gerais, unidades federativas que não aderiram ao protocolo.

Assim, se um estabelecimento situado no Estado de São Paulo vende através da internet um produto a um consumidor final no Ceará, este arrecadará o equivalente a sua alíquota interna subtraída da alíquota interestadual entre São Paulo e Ceará. O Estado de São Paulo, por sua vez, cobrará sua alíquota interna integralmente. Neste caso, a carga tributária global, será a soma das alíquotas cobradas pelos dois entes federados.

Essa situação, considerada à luz dos princípios e normas tributárias, é injusta e ilegal, visto que acarreta bitributação, onerando o consumidor final que acaba pagando a diferença no preço final da mercadoria.

Na opinião de Cezaroti (2005) o comércio eletrônico antes da assinatura do protocolo 21/2011 provocava desequilíbrio na repartição de receitas nas operações interestaduais de mercadorias. Entretanto, no atual cenário os problemas do comércio eletrônico ganham novas feições. De um lado, nas operações entre os centros produtores do país e os estados signatários do protocolo, tem-se a bitributação que onera mais do que o devido as operações interestaduais, consubstanciando um limitador para o comércio nacional e para a circulação de mercadorias e riquezas pelo território. Trata-se de uma situação que reduz a eficiência econômica do país, prejudicando o seu desenvolvimento econômico.

De outro lado, entre os estados não signatários, remanesce o problema da desigualdade de distribuição espacial das empresas praticantes de comércio eletrônico, que resulta em deslocamento de receita tributária de estados consumidores para produtores. Mesmo entre estados do sudeste existe considerável desigualdade a favor do Estado de São Paulo no que diz respeito ao número de estabelecimentos com vendas pela internet. Além da questão quantitativa, existe também o aspecto qualitativo de que dificilmente uma loja online seja exclusivamente uma loja virtual e não seja também uma loja física em seu centro de distribuição. Sendo assim, lojas de centros econômicos maiores e mais dinâmicos tendem a se sobressair sobre seus demais concorrentes nacionais. Essa situação enseja eliminação de intermediários locais no comércio, que não é sequer recompensada por uma maior 
arrecadação dos governos locais. Pelo contrário, estes são duplamente penalizados pela fragilização de seu comércio e pela redução de arrecadação.

\subsubsection{O crédito tributário nas operações de exportação}

Outro relevante problema do modelo adotado na tributação do ICMS nas operações interestaduais é relativo ao crédito tributário nas operações de exportação de mercadorias. A burocracia e a variedade de normas que regulamentam o procedimento de cobrança de ICMS nas operações interestaduais são de complexidade tão grade que conseguem desagradar até mesmo as unidades federativas que, ao menos teoricamente, são beneficiadas pela lógica que premia estados produtores. É o que acontece, por exemplo, no caso da exportação de mercadorias para fora do território nacional que são precedidas de operações interestaduais.

Em procedimento considerado padrão, quando uma empresa compra insumos para produzir um bem, esses insumos possuem ICMS embutido em seu preço. A empresa deve somar quanto pagou de ICMS ao longo do processo produtivo e, ao vender a mercadoria, deve deduzir o ICMS pago do valor que deve recolher na venda do produto.

O problema ocorre quando a mercadoria é exportada. Em consonância com o princípio tributário que não se deve exportar tributos, a Constituição Federal em seu artigo 155, parágrafo $2^{\circ}$, inciso $\mathrm{X}$, alínea $a$, determina que o ICMS não incidirá sobre operações que destinem mercadorias para o exterior, nem sobre serviços prestados a destinatários no exterior, assegurada a manutenção e o aproveitamento do montante cobrado nas operações e prestações anteriores.

Nessas situações, o ICMS recolhido na venda é zero. Entretanto, a empresa não tem como compensar o imposto pago durante a produção. Dessa maneira, ocorre que na prática os produtos exportados, apesar de serem isentos do ICMS na operação final, são comercializados com o valor do ICMS incidente sobre as operações anteriores embutido em seu preço final.

Como não recolheu ICMS na operação de venda, a empresa não consegue abater esse crédito que possui na taxação da operação de venda. Somente em momento posterior é que a empresa pode tentar reaver os valores pagos de ICMS nas operações predecessoras.

Por outro lado, os Estados produtores se recusam a simplesmente trocar esse crédito por dinheiro, visto que os mesmos foram emitidos por outras unidades da federação. Seria o 
caso, por exemplo, de uma fábrica paulista exportadora que comprou insumos de um Estado nordestino. Nesta situação, o Estado do nordeste teria arrecadado, mas São Paulo suportaria os créditos, ou seja, São Paulo teria que devolver um valor que, na prática, não recebeu.

Outro argumento utilizado pelos governos Estaduais é que, como esses valores passíveis de restituição hoje são tão elevados, seria impossível pagá-los integralmente sem um sério dano às finanças públicas.

Em apresentação no Seminário "O Estado e a Federação: crises e reformas", promovido pela Comissão de Assuntos Econômicos do Senado Federal em novembro de 2013, o GETAP (Grupo de Estudos Tributários Aplicados), uma entidade sem fins lucrativos patrocinada por grandes empresas, mostrou que o passivo dos governos estaduais com relação a essa espécie de créditos tributários, em uma estimativa conservadora, pode ultrapassar R\$ 40 bilhões.

Insta salientar que, diferentemente da relação tributária típica, neste tipo de situação tem-se uma relação de crédito invertida, pois o Estado passa a ser devedor e o contribuinte se torna credor, configurando uma obrigação financeira do Estado para com o particular.

Assim, para reaver o crédito, a empresa hoje possui duas possibilidades extraídas do artigo 25, parágrafo $1^{\circ}$, da Lei Complementar 87/96, também conhecida como Lei Kandir. Na primeira, a empresa tem a possibilidade de imputar os saldos credores de ICMS a qualquer estabelecimento seu no Estado. Na segunda, na hipótese de após a operação anterior ainda haver saldo remanescente, a empresa poderá transferir seu crédito a outros contribuintes do mesmo estado, através de documento emitido pelo governo reconhecendo a dívida, o qual permite a cartularização do crédito.

A finalidade da isenção das exportações é, em atendimento ao princípio tributário que não se deve exportar impostos, fazer com que as mercadorias nacionais cheguem ao exterior em condições de competitividade. Por óbvio, a complexidade do procedimento de cobrança do ICMS no país acaba por desvirtuar esse objetivo, visto que as parcelas do imposto cobradas nas operações anteriores à exportação são incorporadas ao preço final do produto brasileiro no exterior e, somente depois, são restituídas às empresas.

Este e alguns outros fatores que serão abordados na próxima sessão constituem o que especialistas em economia denominam de "Custo Brasill". Esse termo alude a um conjunto de dificuldades estruturais, burocráticas e econômicas que retiram a eficiência econômica do país, prejudicando sua competitividade em cenário internacional, sua capacidade de atração de investimentos e, por conseguinte, seu desenvolvimento econômico. 


\subsection{4 $O$ custo de adequação das empresas}

Os custos de adequação das empresas à tributação é outro importante fator do custo Brasil. São componentes desses custos as obrigações acessórias que acompanham a obrigação principal de pagar tributo, o excesso de normas e exceções na legislação tributária e a existência de zonas cinzentas que dificultam a identificação de qual obrigação é de fato devida.

Estes custos podem representar parcela tão significativa das despesas de uma empresa, que várias admitem empregar parte de seus recursos na contratação de especialistas para organizar a produção de modo a legalmente pagar menos tributos. O pagamento desses especialistas pode até ser compensado pela economia de recursos devido ao fisco, entretanto não impede que essa despesa seja mais um elemento do custo do produto que, de um lado não contribuiu para maior arrecadação estatal, de outro tampouco contribuiu para a elevação da qualidade desse produto. Em suma, é mais um aspecto que retira do produto brasileiro a competitividade, hoje tão fundamental no mundo de economias globalizadas.

O excesso de normas e de obrigações tributárias acessórias são partes significativas do custo de adequação das empresas. A descentralização da legislação tributária nas federações, como no caso do ICMS, onera de forma considerável os contribuintes. Se a Constituição Federal estabelecesse que os impostos fossem de competência de vários entes, mas determinando uma legislação nacional e homogênea, economizaria às empresas de porte nacional a necessidade de possuir advogados em cada Estado para consultar a respeito da legislação estadual. Inclusive a guerra fiscal restaria bastante limitada nesta situação.

O custo de adequação das obrigações tributárias acessórias é tão significativo no Brasil, que o Grupo de Estudos Tributários Aplicados (GETAP) no Seminário "O Estado e a Federação: crises e reformas”, promovido pela Comissão de Assuntos Econômicos do Senado Federal em novembro de 2013, apresentou o seguinte ranking de países, expondo o custo médio em horas por ano empregadas no cumprimento de obrigações acessórias:

TABELA 3

Horas por ano empregadas em obrigações acessórias

\begin{tabular}{|ll|ll|}
\hline País & Horas & País & Horas \\
\hline
\end{tabular}




\begin{tabular}{|cc|cc|} 
Suíça & 68 & México & 552 \\
Nova Zelândia & 70 & Espanha & 602 \\
Alemanha & 105 & Armênia & 1120 \\
Inglaterra & 105 & Nigéria & 1120 \\
Suécia & 122 & Camarões & 1300 \\
Dinamarca & 135 & Ucrânia & 2185 \\
Estados Unidos & 325 & Brasil & 2600 \\
Chile & 432 & & \\
\hline
\end{tabular}

Fonte: GETAP (2013)

Este ranking expõe que a situação tributária no Brasil, sem entrar no mérito de sua carga, mas abordando principalmente sua complexidade, representa claramente um entrave à atração de investimentos ao território nacional e, por conseguinte, ao desenvolvimento econômico do país.

Outro fator que contribui sensivelmente para o custo de adequação das empresas é a existência de zonas cinzentas entre os tributos. No Brasil, o IPI (Imposto Sobre Produtos Industrializados), o ICMS e o ISS (Imposto Sobre Serviços) são da competência de três diferentes entes, respectivamente: União, Estados e Municípios. Entretanto, esses impostos, em essência, oneram o consumo, demandam diferentes formalidades que elevam os custos empresariais e possuem zonas de interseção que exigem a contratação de profissionais para a correta identificação do tributo devido, elevando pois os custos.

Bertolucci (2003) entende que boa parte dos custos de conformidade no Brasil é decorrente do próprio pacto federativo e da maneira como a Constituição define a competência tributária, possibilitando 27 diferentes tipos de legislação tributária aos impostos de competência estadual e, no limite, mais de 5.000 com relação aos municípios. Entende o referido autor que para minimizar os custos aos contribuintes seria necessário definir uma legislação federal aplicável a cada imposto, cabendo aos Estados e Municípios a arrecadação através da aplicação dessa legislação.

\section{CONSIDERAÇÕES FINAIS}

O ICMS é o principal imposto incidente sobre o consumo no Brasil. A estrutura mista de cobrança desse imposto permite que nas operações interestaduais parte da arrecadação seja realizada na origem e outra parte no destino. Entretanto, a atual conformação do sistema de 
cobrança desse tributo privilegia os estados produtores (origem). Essa situação é geradora de grandes desigualdades regionais no Brasil.

O vertiginoso crescimento do comércio eletrônico tende a agravar esse problema e a trazer outros problemas como a bitributação. Essa mudança do perfil de consumo das pessoas torna premente a necessidade de se realizar uma reforma fiscal que trate dos problemas gerados pelo mecanismo de cobrança do ICMS nas operações interestaduais abordados neste estudo.

Uma alternativa para combater as disfunções apresentadas por esse modelo seria alterar o enfoque da arrecadação da origem para o destino das mercadorias. Assim, para aumentar a receita, cada ente deverá priorizar o desenvolvimento da capacidade de consumo de sua população.

Entretanto, a gestão da arrecadação é sobremaneira facilitada pelo foco da tributação na origem, sobretudo na atual conformação do sistema produtivo, em que as operações de maior valor são realizadas por poucos grandes grupos empresariais, que controlam estruturas de mercado acentuadamente oligopolizadas. Os órgãos das receitas estaduais propugnam a fiscalização atrelada à produção através da argumentação de maior eficiência técnica, pois ao fiscalizar o foco irradiador da empresa produtora, que antecipa o pagamento do tributo e o repassa ao cliente, poupa-se o custoso trabalho de tributar e fiscalizar as contas de milhares de varejistas.

Essas informações são corroboradas pelo estudo "Justiça Tributária: iniquidades e desafios" do IPEA (2008). Segundo dados deste estudo, 64,32\% da arrecadação tributária nacional são provenientes de grandes empresas, ao passo que 11,31\% provêm de estatais federais e apenas $5,44 \%$ de pequenas empresas.

Essa coerente argumentação não obsta, entretanto, que se elabore um modelo de partilha através de Emenda Constitucional, permitindo que a arrecadação seja efetuada na origem e a receita seja distribuída de acordo com o destino de cada operação, em um eficiente sistema federal de compensação.

Através da adoção dessa sistemática, a concentração de rendas e a desigualdade regional seriam reduzidas. A própria questão da guerra fiscal, não abordada neste artigo, mas que sem dúvida é outro problema entre os principais provocados pela incidência de ICMS nas operações interestaduais, seria apaziguada. Ocorreria perda de autonomia estadual em conceder benefícios tributários para atrair empresas, em prol de um bem maior que é um sistema tributário mais racional, que produza menores custos de adequação aos contribuintes 
e, sobretudo, promova a redução das desigualdades regionais. Um novo ordenamento federal superior harmonizaria interesses locais com interesses nacionais, estabelecendo limites para benefícios e alíquotas, cuja modificação somente seria autorizada pelo crivo de órgãos nacionais, como o Senado.

Essa alteração nas regras do ICMS resultaria, contudo, em redução de receitas para os Estados considerados produtores, o que vai ao encontro dos objetivos fundamentais estampados no artigo $3^{\circ}$ da Carta Magna, mormente no que concerne à redução das desigualdades regionais. Durante o período de transição para as novas regras, como forma de mitigar as perdas destes Estados produtores e proporcionar certo grau de estabilidade para suportar as mudanças, seriam necessários recursos compensatórios através de transferências da União, modificando a distribuição de recursos do pacto federativo.

Esse novo paradigma de tributação sobre o consumo também evitaria o erro de se permitir que questões envolvendo exportação e que, por conseguinte, afetam o balanço de pagamentos nacional, possam envolver idiossincrasias locais, com variedade de procedimentos e normas, passíveis de prejudicar o desempenho internacional do país.

\section{REFERÊNCIAS}

ALEXANDRIA, Francisco Carlos de; CARVALHO, Sérgio Silva de. A repartição do ICMS nas vendas pela internet. Como adequar os princípios constitucionais aos tempos de comércio eletrônico. Jus Navigandi, Teresina, ano 16, n. 2821, 23 mar. 2011.

BATISTA, Luiz Rogério Sawaya. Créditos do ICMS na Guerra Fiscal. São Paulo: Quartier Latin, 2012.

BERTOLUCCI, Aldo Vincenzo. Quanto custa pagar tributos. São Paulo: Atlas, 2003.

CARRAZZA, Roque Antônio. ICMS. São Paulo: Malheiros, 2012.

CARDOSO, Daniel Gatschnigg. Limites da Tributação do Comércio Internacional e Desenvolvimento Econômico. São Paulo: Quartier Latin, 2010.

CEZAROTI, Guilherme. ICMS no Comércio Eletrônico. São Paulo: MP Editora, 2005.

CONFAZ - Conselho Nacional de Política Fazendária. Ministério da Fazenda. Boletim do ICMS e demais impostos estaduais (2012). Disponível em: http://www1.fazenda.gov.br/confaz/boletim/. Acesso em 14/02/2014.

CONSELHO DA UNIÃO EUROPEIA (2006), Directiva 2006/112 de 28 de Novembro, Jornal Oficial $n^{\circ}$ L 347, 11/12/2006. Disponível em: <http://eur-lex.europa.eu/LexUriServ/L exUriServ.do?uri=CONSLEG:2006L0112:20100115:pt:PDF> 
DERZI, Mizabel Abreu Machado. Não cumulatividade, Neutralidade, PIS e COFINS e a Emenda Constitucional no 42/03, In: Grandes Questões Atuais do Direito Tributário. São Paulo: Dialética, 2004.

DERZI, Mizabel Abreu Machado; COÊLHO, Sacha Calmon Navarro. O aspecto espacial da regra-matriz do Imposto Municipal sobre Serviços, à luz da Constituição. In: Revista Dialética de Direito Tributário, São Paulo, v.88, jan. 2003, p. 137.

GETAP. IVA e Tributação na Federação. In: Seminário O Estado e a Federação - Crises e Reformas, Comissão de Assuntos Econômicos do Senado Federal, 2013, Brasília.

IBGE. Contas regionais do Brasil 2011. Disponível em: <http://www.ibge.gov.br/home/ presidencia/noticias/imprensa/ppts/00000015422711192013272921125925.pdf >. Acesso em: $14 / 02 / 2014$.

IBGE. Estimativas de população para $1^{\circ}$ de julho de 2012. Disponível em: <http://ww w.ibge.gov.br/home/estatistica/populacao/estimativa2012/estimativa_dou.shtm>. Acesso em: $14 / 02 / 2014$.

IBGE. Pesquisa Nacional por Amostra de Domicílios 2011-2012, Rio de Janeiro, v. 32, p.1$134,2012$.

IPEA. Apresentação Justiça Tributária: Iniquidades e Desafios. Brasília: IPEA, maio 2008. Disponível em: http://www.oeconomista.com.br/arquivos/tributos_ipea_maio_2009.pdf Acesso em: 14/02/2014.

KRUGMAN, Paul. Internacionalismo Pop. São Paulo: Editora Campus, 1999.

KUBOTA, Luis Claudio; MILANI, Daniele Nogueira. Os efeitos do e-commerce na produtividade das firmas comerciais no Brasil. 1585 - Texto para discussão. Brasília: IPEA, 2011.

LEVI, Margareth. Of Rule and Revenue. Berkley: University of California Press, 1989.

LONGO, Carlos Alberto; TROSTER, Roberto Luis. Economia do Setor Público. São Paulo: Atlas, 1993.

MARTINS, Marcelo G. Tributação, propriedade e igualdade fiscal. Rio de Janeiro: Elsevier, 2011.

MINISTÉRIO DA FAZENDA. O Brasil e o comércio eletrônico. Brasília: Receita Federal, 2001.

MOSQUERA, Roberto Quiroga. Tributação e Política Fiscal. In: Segurança Jurídica na tributação e estado de direito. São Paulo: Noeses, 2005.

MUSGRAVE, Richard A. Teoria das Finanças Públicas. São Paulo: Atlas, 1974.

O’CONNELL, Brian. B2B.com. Ganhando dinheiro no e-Commerce Business-to-Business. São Paulo: Makron Books, 2002. 
OCDE. Revenue Statistics in Latin America. OECD Publishing, 2014.

OLIVEIRA, Luiz Guilherme de. Federalismo e guerra fiscal. São Paulo: Pulsar, 2000.

OLIVEIRA, Mauro Márcio. Fontes de informações sobre a Assembléia Nacional Constituinte de 1987: quais são, onde buscá-las e como usá-las. Brasília: Senado Federal, 1993.

STIGLITZ, Joseph E. Economics of the public sector. 3rd edition. Nova York/Londres: W.W. Norton and Company, 1999. 